\title{
The IL-2/CD25 Pathway Determines Susceptibility to T1D in Humans and NOD Mice
}

\author{
Calliope A. Dendrou $\cdot$ Linda S. Wicker
}

Received: 24 June 2008 / Accepted: 1 July 2008 /Published online: 9 September 2008

(C) The Author(s) 2008. This article is published with open access at Springerlink.com

\begin{abstract}
Although the interleukin-2 (IL-2)/IL-2R signaling pathway has been the focus of numerous studies, certain aspects of its molecular regulation are not well characterized, especially in non-T cells, and a more complete understanding of the pathway is necessary to discern the functional basis of the genetic association between the IL-2-IL-21 and IL-2RA/CD25 gene regions and T1D in humans. Genetic variation in these regions may promote T1D susceptibility by influencing transcription and/or splicing and, hence, IL-2 and IL-2RA/CD25 expression at the protein level in different immune cell subsets; thus, there is a need to establish links between the genetic variation and immune cell phenotypes and functions in humans, which can be further investigated and validated in mouse models. The detection and characterization of genetically determined immunophenotypes should aid in elucidating disease mechanisms and may enable future monitoring of disease initiation and progression in prediabetic subjects and of responses to therapeutic intervention.
\end{abstract}

Keywords Type 1 diabetes $\cdot$ NOD mice $\cdot$ CD25 . IL-2RA $\cdot$ IL-2

C. A. Dendrou $\cdot$ L. S. Wicker $(\bowtie)$

Juvenile Diabetes Research Foundation/Wellcome Trust Diabetes and Inflammation Laboratory, Department of Medical Genetics,

Cambridge Institute for Medical Research,

University of Cambridge, Addenbrooke's Hospital,

WT/MRC Bldg, Hills Road,

Cambridge CB2 OXY, UK

e-mail: linda.wicker@cimr.cam.ac.uk

\section{Genetic Control of Type 1 Diabetes}

The discovery several decades ago of the association of type 1 diabetes (T1D) with the major histocompatibility complex (MHC) human leukocyte antigen (HLA) class II (chromosome 6p21) region convinced most investigators that T1D was an autoimmune disease [1-3]. This caused a fundamental shift in research focused on preventing T1D, and several trials using the immunosuppressive drug cyclosporine were conducted. Although cyclosporine could reverse T1D in new onset patients, an observation that reinforced the concept that immune cells mediate T1D, the disease emerged almost immediately after drug withdrawal, and moreover, long-term immunosuppression as a cure for T1D has more potentially life-threatening complications than T1D itself [4]. The search for more clues about the pathogenesis of T1D from cellular immunological studies and from the discovery of additional T1D genes characterized much of T1D research in the following decades. The search for other genes with effects on disease susceptibility as large as those of the HLA class II genes failed, and results from the nonobese diabetic (NOD) mouse model of T1D indicated that many genes outside of the MHC influence disease susceptibility [4]. The belief that a greater understanding of the genetics underlying T1D would illuminate disease etiology inspired several investigators to accumulate even larger numbers of DNA samples from T1D patients and controls as well as from T1D families to perform candidate gene association studies $[5,6]$.

Before recent advances from genome-wide association studies (GWAS) that have associated additional regions with T1D [7, 8], there were four non-MHC genes associated with human TID: the insulin gene (on chromosome 11p15) [9], the cytotoxic T-lymphocyte-associated antigen-4 (CTLA-4) gene (on 2q33) [10], the PTPN22 gene 
(on 1p13) [11-13], and the interleukin-2 receptor alpha chain (IL-2RA/CD25) gene region (on 10p15) [14, 15]. All four associations emerged from candidate gene studies, and studies on the CD25 gene, which encodes the inducible alpha subunit of the IL-2 receptor, were in part inspired by results from the NOD mouse model showing that a strong genetic effect for T1D mapped to the chromosome 3 region encompassing the IL-2 gene (Idd3) [16, 17]. Mice possessing T1D susceptibility alleles at Idd3 have reduced IL-2 levels in comparison to mice with C57BL/6 (B6)-derived resistance alleles [18], with this allelic variation of the IL-2 gene having at least 46 associated SNPs near and in the gene, resulting in a twofold reduction in IL-2 expression [19]. Data supporting the hypothesis that particular SNPs upstream of the minimal promoter of the IL-2 gene can alter the transcriptional activity of the gene have also been presented [20].

In humans, the T1D-association in the gene region encompassing IL2RA was first discovered by Vella et al. [15], using a tag SNP approach [21, 22]: A strong statistical evidence for an association in the region was found $(P=$ $6.5 \times 10^{-8}$ ), and this finding was later replicated by Qu et al. [23] in an independent family collection. The association of $I L 2 R A$ with T1D has been further verified in a large-scale genetic fine-mapping study by Lowe et al. [14] that localized the T1D association in the region to two independent SNP groups (groups 1 and 2, Fig. 1). The groups span 14- and $40-\mathrm{kb}$ overlapping regions that encompass IL2RA intron 1 and the $5^{\prime}$ regions of IL2RA and $R N A$ binding motif protein (RBM17; OR $=2.04,95 \%$ $\left.\mathrm{CI}=1.70-2.45, P=1.92 \times 10^{-28}\right)$. As the two SNP groups found by Lowe et al. [14] localized to a region centered on the $5^{\prime}$ region of both $I L 2 R A$ and $R B M 17$, one or both SNP groups could affect either of the genes; however, IL2RA is the favored candidate because of its known immunological relevance. Six positive regulatory regions and two negative regulatory elements have been found to be involved in the regulation of IL2RA expression [24]. Lowe et al. [14] resequenced these regions and found no associated SNPs in any of the known regulatory elements, suggesting that disruption of one of these regions is not the cause of the disease association. However, the SNPs may potentially affect $\mathrm{CpG}$ dinucleotides [14], noting that $\mathrm{CpG}$ dinucleotide methylation is important in gene transcriptional regulation [25]. The genome-wide mapping technique used by Roh et al. [26] has also identified high acetylation levels in the IL2RA $5^{\prime}$ region in both resting and activated $\mathrm{T}$ cells, and one or more of the associated SNPs may be implicated in histone remodeling and, thus, in IL2RA transcription. It is also interesting to note that recently, the Wellcome Trust Case-Control Consortium completed a GWAS involving a scan of 500,000 SNPs across the genome, which showed a significant association between T1D and six previously unknown chromosome regions $\left(P<5 \times 10^{-7}\right)$, including $4 \mathrm{q} 27$, which contains the IL-2 and IL-21 genes; further fine-mapping is required, however, to better localize the association within this region [8].

\section{Influence of the IL-2/IL-2RA Pathway in Autoimmunity and Tolerance}

The genetic evidence that the IL-2/IL-2R pathway is involved in the development of T1D in both humans and mice raises questions concerning how functional variation of this pathway can promote T1D susceptibility and whether the precise mechanisms involved are conserved between species. Moreover, might variation in these pathways alter susceptibility to autoimmune diseases in addition to T1D?

IL- $2^{-/-}$knockout mice develop autoimmunity, including a type of inflammatory bowel disease [27-29], while mice deficient in CD25 show an initial normal lymphoid development, but subsequently develop peripheral lymphoid organ enlargement as polyclonal $\mathrm{T}$ and $\mathrm{B}$ cells undergo expansion and activation-induced cell death
Fig. 1 IL2RA locus and the T1D-associated SNP groups. The IL-2RA gene is found on chromosome region $10 \mathrm{p} 15$. Two groups of SNPs, found in the intron 1 and $5^{\prime}$ regions of IL2RA are independently associated with $\mathrm{T} 1 \mathrm{D}(\mathrm{OR}=2.04,95 \% \mathrm{CI}=$ $\left.1.70-2.45, P=1.92 \times 10^{-28}\right)[14]$

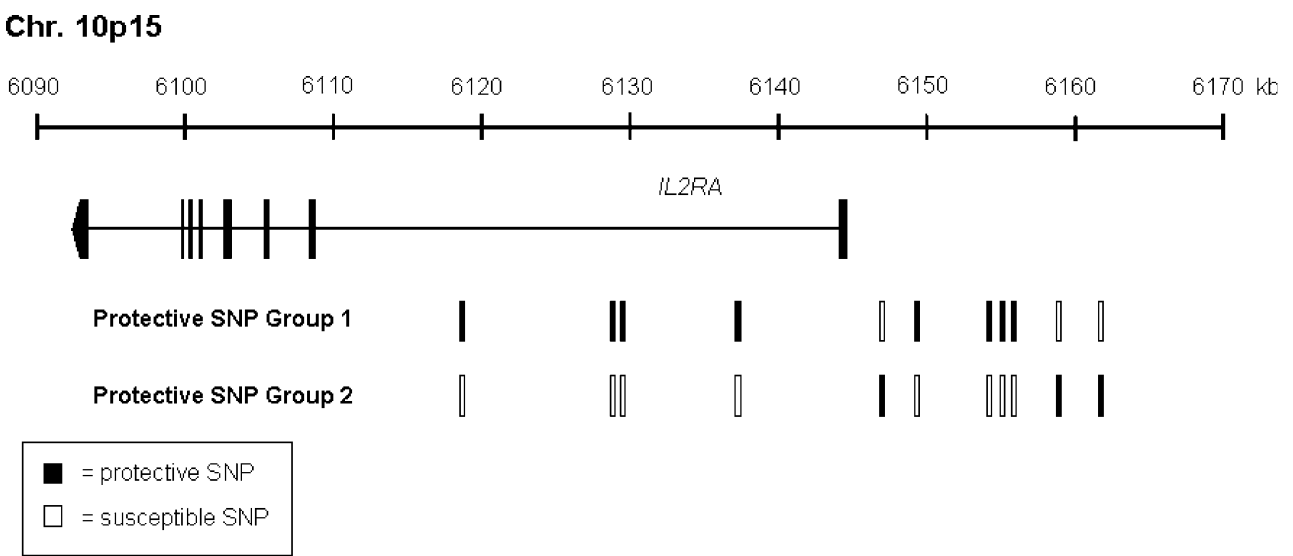


(AICD) is impaired, and with age autoimmunity develops [30]. These observations are consistent with the development of T1D in NOD mice associated with reduced IL-2 levels $[18,19]$, and furthermore, $I d d 3$ alleles are known to affect the development of a number of other autoimmune diseases, including autoimmune ovarian dysgenesis [31], experimental autoimmune encephalomyelitis [32], and Sjögren's syndrome-associated manifestations [33, 34]. In addition, experiments utilizing $I d d 3$ congenic mouse strains demonstrated that mice with $I d d 3$ susceptibility alleles have reduced sensitivity to tolerance induction to allogeneic [35] and xenogeneic [36] islet grafts. Similarly, protective alleles at $I d d 3$ and $I d d 5$ facilitated islet-antigen specific tolerance as compared with NOD mice; the proliferation of autoreactive $\mathrm{CD}^{+} \mathrm{T}$ cells was greatly reduced in the pancreatic lymph nodes (PLNs) upon activation by cross-presented islet antigens and migration to the islets appeared to be eliminated [37].

In humans, van Heel et al. [38] have found evidence of an association in the IL2-IL21 region with celiac disease $\left(P=1.3 \times 10^{-14}\right)$, and this group also found an association in this region with rheumatoid arthritis and confirmed the initial T1D association found by Todd et al. [8], in an independent case-control cohort [39]. Todd et al. [8] also found evidence of an association in this region with autoimmune thyroid disease (Graves' disease). Similarly, apart from its association with T1D, the IL2RA region has been found to be associated with Graves' disease [40], rheumatoid arthritis [7], and multiple sclerosis [41] through GWAS, and rare IL2RA mutations cause severe autoimmune disease $[42,43]$.

Thus, there is increasingly strong evidence supporting the hypothesis that genetic variants in the IL-2/IL-2R pathway play a critical role in the balance between tolerance and autoimmunity. Although for many of the above autoimmune diseases fine-mapping is required to find the most associated SNP or group of SNPs, once each independent allele is identified, the process of understanding the mechanism by which the likelihood of breaking self-tolerance is altered by genetic variation at the IL2-IL21 and/or IL2RA regions will require identification of genotype-phenotype correlations for each allele. It is even possible that an allele that is protective for one autoimmune disease would be neutral or confer susceptibility to another depending on aspects of the two disease processes such as disease location, the effector cells and mechanisms used to destroy the targeted self-tissues, and the subsets of regulatory cells engaged to counter each disease. To begin to understand how genetic variation may alter function and lead to disease susceptibility or resistance, we need to consider what is already known about the molecules in question, and about the cellular consequences of their interaction.

\section{IL-2/IL-2R Transcriptional Regulation: Splicing}

As the two groups of T1D-associated SNPs in the IL2RA region are found in noncoding regions, they could influence overall CD25 transcript levels or splicing; indeed, levels of alternatively spliced CTLA-4 forms vary by genotype and are associated with T1D susceptibility in both humans and mice [10]. A genotype-associated alteration in the mRNA splice form levels of BANK1, a gene associated with systemic lupus erythematosus, has also been reported [44].

The full-length, 55-kDa CD25 glycoprotein is encoded by eight exons. The first studies indicating that CD25 has alternative splice forms identified a splice form lacking exon $4(\Delta 4)[45,46]$. The $\Delta 4$ protein isoform was further characterized by Neeper et al. [47]: Unlike full-length $\mathrm{CD} 25$, the $\Delta 4$ isoform was incapable of binding IL-2. Horiuchi et al. [48] also provided evidence for another alternatively spliced mRNA from IL2RA encoding an isoform lacking the amino acids encoded by exons 5 to 7 , which includes the transmembrane region, and is presumably secreted.

A study by Eicher et al. [49] used different IL-2RA/ CD25 constructs lacking specific exons to investigate some of the characteristics of the regions encoded by the various exons in IL-2R subunit oligomerization. This work is of particular interest in light of the potential existence of several CD25 isoforms. The trimeric IL-2R comprises CD25 (Fig. 2a), the IL-2R $\beta$ chain (IL-2RB/CD122) (which is shared with IL-15R), and the common $\gamma$ chain (IL-2RG/ CD132) (which is also shared by IL-4, IL-7, IL-9, IL-15, and IL-21 receptors). By using CD25 constructs, it was determined that a deletion of exon 4 , but not exons 5 or 6 , resulted in an $\alpha$ chain that showed an absence of the IL-2induced oligomerization response typically observed when full-length CD25 was coexpressed with IL-2RB or with IL$2 \mathrm{RB}$ and IL-2RG. Interestingly, it was also observed that, when full-length CD25 was expressed alone, a high baseline reporter signal for oligomerization was detected, indicating that CD25 can undergo a spontaneous, cytokineindependent oligomerization, and this phenomenon was confirmed by fluorescence resonance energy transfer (FRET) analysis. The spontaneous CD25 homo-association was attenuated upon deletion of exon 6 , but not exons 4 or 5 [49]. Hence, it seems likely that CD25 splice isoforms may differ in certain functional aspects compared to the full-length form, and it remains to be determined whether any splice isoform variation is correlated with T1D susceptibility.

Although alternatively spliced IL-2 mRNAs have not been studied in the context of autoimmunity, two alternatively spliced IL-2 mRNAs have been identified in humans. These two produce proteins lacking the amino acids encoded by exons 2 and 3, respectively, and act as 
Fig. 2 The IL-2R subunits, their affinities for IL-2, and the expression of the cytokine and its receptor by multiple immune cell types. a CD25 (IL-2R $\alpha$ ) alone has a low affinity for IL-2, it is incapable of intracellular signaling and may be found at the cell surface as a monomer or homodimer. Upon immune-cell activation $\mathrm{sCD} 25$ is generated by proteolytic cleavage. The high-affinity trimeric IL-2R comprises CD25, IL-2R $\beta$, and the common $\gamma$ chain (IL-2R $\gamma$ ). The heterodimer of IL-2R $\beta$ and IL-2R $\gamma$ is also capable of binding IL-2, but with an intermediate affinity. b Although the IL-2/IL-2R interaction has been most studied in T cells, IL-2 and its high or intermediate affinity receptors are expressed by various immune cell types a

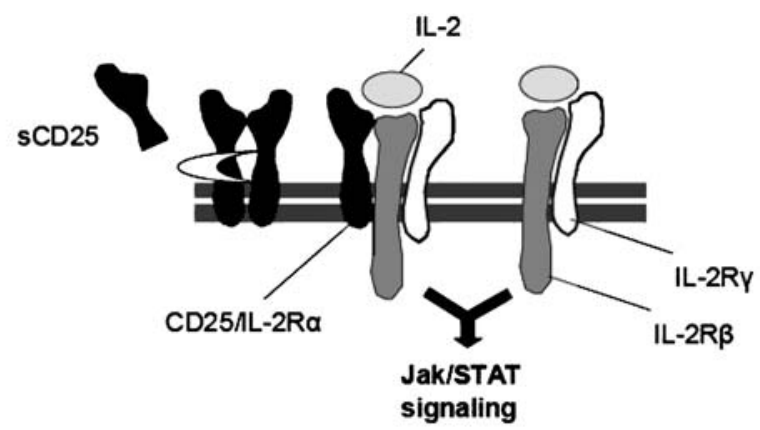

\begin{tabular}{|c|c|c|c|}
\cline { 2 - 4 } \multicolumn{1}{c|}{} & $\alpha$ & $\alpha \beta Y$ & $\beta Y$ \\
\hline Affinity & Low & High & Intermediate \\
\hline $\mathrm{K}_{\mathrm{d}}[\mathrm{M}]$ & $10^{8}$ & $10^{-11}$ & $10^{9}$ \\
\hline
\end{tabular}



competitive inhibitors of full-length IL-2, blocking its ability to costimulate $\mathrm{T}$ cell proliferation and bind to the trimeric IL-2R, in a dose-dependent fashion [50].

\section{The IL-2/IL-2R Complex and Downstream Signaling}

CD25 alone has a low affinity $\left(K_{\mathrm{d}} \sim 10 \mathrm{nM}\right)$ for IL-2 [51]. The dimer of IL-2RB and IL-2RG is also capable of binding IL-2 with an intermediate affinity $\left(K_{\mathrm{d}} \sim 1 \mathrm{nM}\right)$ [46]. The high-affinity trimeric IL-2R complex has a $K_{\mathrm{d}}$ of $\sim 10$ pM [52] (Fig. 2a). Rickert et al. [53] solved the crystal structure of IL-2 bound to CD25. CD25 has two extracellular domains (D1 and D2) that are homologous to a set of $\beta$-sandwich protein domains known as sushi domains, complement control protein repeats or short consensus repeats $[54,55]$. The structure of the trimeric IL-2R ectodomains bound to IL-2 has been solved by Wang et al. [70] and, subsequently, by Stauber et al. [56]. Interest- ingly, CD25 does not contact either IL-2RB or IL-2RG (noting that only the ectodomains of the receptor chains were present); Wang et al. [57] proposed that the basis of the cooperativity of the trimeric receptor is a decrease in entropy whereby CD25 binds and concentrates IL-2 at the cell surface for presentation to IL-2RB and IL-2RG, or alternatively, a CD25-induced alteration in IL-2 conformation may occur, hence stabilizing the complex [57].

When IL-2-induced oligomerization of the trimeric IL$2 \mathrm{R}$ occurs, this results in the activation of the JAK1 and JAK3 cytoplasmic protein tyrosine kinases that are associated with the intracellular domains of IL-2RB and IL-2RG, respectively. These kinases then phosphorylate certain IL$2 \mathrm{RB}$ tyrosine residues that act as docking sites for signal transducer and activator of transcription (STAT)5a and STAT5b, for example [58]. The IL-2-induced activation of numerous signaling pathways eventually results in the transcription of target genes that contribute to the many functions associated with the IL-2/IL-2R pathway [59-61]. 
There is also some evidence that $\mathrm{CD} 25$ on one cell can present IL-2 to IL-2RB/IL-2RG dimers on another cell, in a high-affinity, intercellular interaction [62]. Even though the signal transduction cascades downstream of the IL-2/IL-2R binding event have been quite extensively studied in $\mathrm{T}$ cells, much remains to be elucidated with respect to the status of these downstream pathways in non-T cells.

\section{The IL-2/IL-2R Pathway and T cell Function}

The IL-2/IL-2R signaling pathway is known to have a pleiotropic role in $\mathrm{T}$ cell biology, and the in vivo necessity for this signaling pathway according to $\mathrm{T}$ cell type and function has been recently reviewed [61]. In 1980, Mier and Gallo [63] identified IL-2 as an autocrine factor necessary for the long-term culture of $\mathrm{CD}^{+} \mathrm{T}$ cells, and the involvement of IL-2 in T cell responses is widely accepted. The activation of $\mathrm{T}$ cells through their $\mathrm{T}$ cell receptor (TCR) along with costimulatory signaling results in the production of IL-2 and the expression of the IL-2R at the cell surface. The interaction of the cytokine with its receptor results in clonal expansion and the differentiation of effector cells [61, 64], as this interaction drives a STAT5dependent positive feedback loop that induces CD25 upregulation and, hence, increased signaling through augmented IL-2 capture by its receptor on the activated T cells [65]. IL-2R-induced signaling also leads to repression of IL-2 transcription, whereby IL-2 negatively regulates its own production [66, 67]. In addition to downregulating its own generation, IL-2 alters the immune response by causing $\mathrm{T}$ cells to become susceptible to apoptosis following a further strong TCR cross-linking that increases the expression of death-mediating molecules in the Fas and tumor necrosis factor (TNF) pathways, in a process termed AICD [68].

Although these findings support the involvement of the IL-2/IL-2R pathway in the development of immune responses, IL-2- or CD25-deficient mice are still capable of developing effective immune responses in vivo upon antigenic challenge [61, 69], suggesting that this pathway may actually be dispensable. One difficulty in interpreting studies using such mice is that the autoimmunity associated with the lack of IL-2 or CD25 may provide a confounding setting in which a requirement for IL-2 may be circumvented. Yet this does not seem to be the case: For example, TCR-transgenic IL-2- or CD25-deficient mice (that in some cases have been further crossed with Rag knockout mice) $[70,71]$ have little or no autoimmune disease, but they are still capable of developing effective immunity despite the lack of IL-2/IL-2R signaling, suggesting that this signaling pathway may indeed have a redundant role in the elicitation of an immune response [61, 69]. However, there is some evidence that IL-2/IL-2R signaling may be mandatory in the $\mathrm{CD}^{+}$memory $\mathrm{T}$ cell responses associated with longlasting $\mathrm{T}$ cell immunity [72, 73], and in light of the possibility of compensatory mechanisms to become enhanced when IL-2 or CD25 are deficient, the true contribution of IL-2/IL-2R signaling in T cell responses in vivo remains to be determined.

Apart from its function in stimulating effector T cells, the IL-2/IL-2R pathway also has a role in the maintenance of self-tolerance. CD25 is constitutively expressed at high levels on $\mathrm{CD}^{+}{ }^{+} \mathrm{Foxp}^{+}{ }^{+}$regulatory $\mathrm{T}$ cells (Tregs), which suppress putatively autoreactive peripheral $\mathrm{T}$ cells that escape thymic deletion during the establishment of central tolerance [74-77], and Treg depletion causes autoimmunity in mouse models [78]. Foxp3 is a transcription factor that is fundamental for Treg production and function [79-81]: Targeted ablation of the Foxp3 gene results in severe autoimmune manifestations in mice, and in humans, natural mutations of the orthologous gene lead to immune dysregulation, polyendocrinopathy, enteropathy, and Xlinked inheritance (IPEX) syndrome [82-84] and X-linked autoimmunity-allergic dysregulation syndrome [85]. A notable feature of Tregs is their inability to produce IL-2, even upon TCR stimulation [86], and this transcriptional repression is mediated by Foxp3 and its interaction with NFAT and AML1/Runx1 [87, 88]. The interaction of Foxp3 with these transcription factors is generally responsible for the establishment of the Treg signature, which includes the high expression of $\mathrm{CD} 25$ [87, 88]. The incapacity to produce IL-2 themselves along with their high CD25 levels renders Tregs uniquely sensitive to paracrine IL-2, and this raises questions regarding the detailed mechanisms by which the IL-2/IL-2R pathway contributes to Treg development and function.

Natural Tregs develop in the thymus, and this development requires binding of self-antigen to the TCR and costimulation through CD28 [89, 90], the latter contributing to Foxp3 induction and to the production of IL-2 by other T cells that may act as a paracrine supply of the cytokine for the developing Tregs [91]. IL-2 has been shown to increase Foxp3 levels [92], and as the development and maintenance of Tregs rely on the sustained, high expression of Foxp3, the IL-2/IL-2R pathway may indeed be involved in Treg generation and lineage commitment. Interestingly, utilizing an ins-HEL TCR transgenic mouse model, it has been demonstrated that IL-2 plays a critical role in the level of autoantigen-specific Tregs that are selected in the thymus and thus found in the periphery, and it has been suggested that IL-2 promotes the development of Tregs with a high avidity for self, which may be more efficient in suppressing autoreactive $\mathrm{T}$ cells [93]. Apart from the thymic-derived Tregs, conventional $\mathrm{T}$ cells can become Foxp $3^{+}$-induced Tregs in the periphery [94], and considering the potential 
role of IL-2/IL-2R signaling in natural Treg development, it seems likely that this pathway may be involved in the generation of these induced Tregs. In addition, the IL-2/IL$2 \mathrm{R}$ interaction is required by Tregs in the periphery for the maintenance of their homeostasis and competitive fitness in vivo [95].

\section{$\mathrm{CD}^{+} \mathrm{CD}^{\mathrm{hi}}{ }^{\mathrm{Foxp}}{ }^{+}$Tregs and T1D}

Given the importance of Tregs in peripheral tolerance, the involvement of the IL-2/IL-2R pathway in their development and function, and the genetic association of components of this pathway with T1D in both humans and mice, the Treg population has been much studied in the context of this autoimmune disease.

Treg depletion or blocking of the B7/CD28 pathway (which decreases Treg frequency) in NOD mice leads to accelerated disease onset $[89,90]$, as does IL-2 neutralization [96]. Furthermore, T1D resistance in aged NOD mice has been correlated with Treg expansion in PLNs [97, 98], and Foxp3-deficient NOD mice show earlier onset and a higher incidence of T1D compared to normal NOD mice [99]. More recently, Tritt et al. [100] have investigated the frequency and function of Tregs in the primary and secondary lymphoid tissues in the NOD mouse model; the researchers found no differences in Treg numbers between T1D-susceptible and T1D-resistant mice, and although the Tregs did not affect the priming or initial expansion of diabetogenic $\mathrm{T}$ cells, they did influence the differentiation of these cells in the PLNs.

Yamanouchi et al. [19] provided direct evidence that IL-2 affects Tregs in the context of T1D by showing that diabetes susceptibility associated with a NOD allele at Idd3 is indeed because of allelic variation of the IL-2 gene, with an approximately twofold reduction in expression correlating with disease. Engineered haplodeficiency of IL-2 gene expression also reduced IL-2 production by $\mathrm{T}$ cells and resulted in dysregulatory effects similar to those of the naturally occurring $I l 2$ diabetes susceptibility alleles. Moreover, either the natural or engineered deficiency of IL-2 production correlated with reduced Treg function. In accordance with this, Tang et al. [101] found a progressive decline in the number of Tregs relative to effector T cells in inflamed NOD mouse islets (but not in the PLNs), with the intra-islet Tregs expressing decreased amounts of CD25 and Bcl-2, indicating a Treg decrease in numbers by apoptosis, potentially because of an IL-2 deficiency, as IL-2 can induce both CD25 and Bcl-2 in T cells [102]. The administration of low-dose IL-2 was capable of promoting Treg survival (noting that these Tregs had high levels of CD25) and preventing diabetes.
In humans, several studies have reported either numerical [103] or functional [104, 105] defects in the Treg population in T1D patients, while one study suggests no Treg-related defects at all [106]. Tree et al. [107] have collectively considered these conflicting results and suggest that the numerical deficiency in Tregs observed by Kukreja et al. [103] may be because of the methodology by which this cell population was defined and the fact that the ages of their T1D patients and controls were significantly different. Recently, Brusko et al. [108] have more extensively investigated Treg frequency and absolute numbers in long-standing and new-onset T1D patients, their relatives and healthy controls with no significant differences being found. Notably, Treg frequency was determined to be age independent [108], and there is some evidence that Tregs are maintained by the rapid turnover of memory populations in vivo [109]. Although, in mice, Foxp3 is only expressed in Tregs [95], in humans, transiently activated effector $\mathrm{T}$ cells can also express the transcription factor [110], and thus, definitive Treg identification requires functional testing for suppressive capability. In relation to Treg functional defects in T1D patients, Tree et al. [107] indicate that the discordance between studies may be because of the different stimulatory conditions utilized in the assays measuring suppressive capacity. It has been shown that the strength of stimulation used to activate effector $\mathrm{T}$ cells can greatly affect the suppressive capacity of Tregs [111], with increasing $\mathrm{T}$ cell signal strength reducing the Treg suppressive capability [112]. Hence, Brusko et al. [104] and Lindley et al. [105] may have been able to observe a defect in Tregs from T1D patients because of the precise stimulatory conditions used. To date there has been no investigation of Treg number or function in relation to genetic variation at the IL2RA or IL2-IL21 regions in humans.

\section{Non-regulatory $T$ cells and T1D}

Apart from a potential IL-2/IL-2R-associated defect in Treg numbers and/or function, an alternative, although not mutually exclusive, possibility is that an IL-2/IL-2Rassociated defect in effector $\mathrm{T}$ cells renders them resistant to Treg suppression, therefore, resulting in a breakdown of peripheral tolerance that promotes susceptibility to T1D. Indeed, an acquisition of resistance to suppression by effector $\mathrm{T}$ cells with time as diabetes progresses in NOD mice has been observed [113-115]. A study by Waithman et al. [116] indicates that the provision of IL-2 signaling through the use of an activatory anti-IL-2 antibody-IL-2 complex can drive tolerant, naive $\mathrm{T}$ cells toward autoimmunity, and memory $\mathrm{T}$ cells were also found to upregulate CD25 subsequent to self-antigen recognition. These results 
suggest that enhanced IL-2 signaling can induce autoimmunity, and when considered along with the IL-2 deficiency associated with T1D susceptibility at $I d d 3$, these otherwise paradoxical findings imply that there is a fine balance between tolerance and autoimmunity and that there is a necessity for the maintenance of an optimal level of IL-2/IL-2R signaling, given the multiple functions of this pathway.

The role of nonregulatory $\mathrm{T}$ cells in human T1D has focused primarily on the antigen-specificity of the effector T cells, although a correlation has been identified between genotype at the IL2RA region and soluble CD25 (sCD25) [14]. SCD25 is considered to be a marker of immune-cell activation as increased amounts, above the basal circulating level, are observed during acute graft rejection or infections [117]. Although alternatively spliced mRNA species can encode non-membrane bound CD25 as discussed above, it has been postulated that most of the sCD25 found in the blood is generated by proteolytic cleavage as $\mathrm{T}$ cells become activated and proliferate [118], and there is conflicting evidence regarding its monomeric [119] or dimeric [120] nature under physiological conditions. Tregs proliferate in vivo more quickly than do non-Treg $\mathrm{CD}^{+} \mathrm{T}$ cells $[109,121-123]$ suggesting the possibility that Tregs contribute to blood levels of sCD25. Competitive binding studies indicate that sCD25 binds IL-2 with low affinity [124], although in vivo functional properties remain to be elucidated. The half-life of sCD25 is about $40 \mathrm{~min}$ in the circulation [125], and it has been suggested that $\mathrm{sCD} 25$ inhibits bioactive IL-2 [126-128]. Kobayashi et al. [125] have evaluated the extent of the protection from degradation conferred by sCD25 on IL-2. sCD25 was found to protect IL-2 from in vitro inactivation.

Lowe et al. [14] measured the total sCD25 concentration in plasma samples from 1,357 T1D cases and found that susceptibility at the IL2RA region was significantly associated with lower sCD25 levels $\left(P=6.28 \times 10^{-28}\right)$. The functional significance of this lower level of sCD25 in T1D patients with susceptibility alleles at IL2RA is unknown, but it could suggest a reduced $\mathrm{T}$ cell activity and/or proliferation, which is potentially indicative of a lowered state of $\mathrm{T}$ cell responsiveness in vivo, and which might, very speculatively, be consistent with the Idd3associated IL-2 deficiency observed in NOD mice. Such hyporesponsive $\mathrm{T}$ cells have been reported in T1D patients in vitro [129] and in rodent autoimmune-prone models ex vivo [130]. However, much remains to be determined regarding the significance of the IL2RA genotype-sCD25 correlation; any functionality of $\mathrm{sCD} 25$ is unknown, as is the actual cellular origin of it, as there is evidence that non-T cells can also produce it (see the next section).
The IL-2/IL-2R Pathway in Other Immune Cell Types

Even though the function of the IL-2/IL-2R pathway has been most studied in $T$ cells historically, there is now increasing evidence from work in both humans and mice that this pathway has a much broader immunological function (Fig. 2b) that needs to be investigated with respect to the function of the genetic variants in the IL-2/IL-2R pathway that influence T1D and other autoimmune diseases.

Aside from T cell-related IL-2 production, dendritic cells (DCs) also produce IL-2 upon activation with microbial stimuli [131], and natural killer (NK) and NKT cells are capable of generating the cytokine as well $[96,132,133]$. Although the functional consequences of NK- and NKTcell IL-2 production are not clear, DC-associated IL-2 secretion plays an important role in $\mathrm{T}$ cell priming: Granucci et al. [131] found that mouse IL- $2^{-/-}$DCs were impaired in their ability to induce $\mathrm{CD} 4^{+}$and $\mathrm{CD} 8^{+} \mathrm{T}$ cell proliferation. Feau et al. [134] subsequently showed that human myeloid and plasmacytoid DCs could also produce IL-2, and they showed that this production was regulated by IL-15 in both humans and mice. The ability of DCs to produce IL-2 raises the question of whether the cytokine may affect these cells in an autocrine manner, rather than acting only as a paracrine factor. Both human and mouse DCs have been found to express CD25 at their plasma membrane $[135,136]$. Work by Naranjo-Gomez et al. [137] indicates that $\mathrm{CD} 25$ can be quickly upregulated on CpGand CD40L-activated human plasmacytoid DCs within $6 \mathrm{~h}$ of activation, and the administration of exogenous IL2 increases the secretion of pro-inflammatory cytokines such as TNF- $\alpha$, as well as plasmacytoid DC survival. Mnasria et al. [138] used lipopolysaccharide (LPS) to upregulate CD25 at the surface of myeloid DCs, and the addition of antagonistic anti-CD25 antibodies to the LPS stimulation resulted in decreased production of pro-inflammatory cytokines and impaired ability of the DCs to prime $\mathrm{T}_{\mathrm{H}} 1$ cells. Hence, IL-2/IL-2 signaling is important in DCs themselves, for their survival and for the generation of appropriate inflammatory and adaptive immune responses.

Physiologically, the intercellular presentation of IL-2 may play a role in disseminating IL-2-mediated T cell/DC activation and in activating bystander IL-2RB/IL-2RGexpressing cells. Such cells include NKT cells [139], and NK cells, whose activity is augmented upon IL-2 administration [140-142], and it has more recently been shown in mice that myeloid DC-derived IL-2 directly acts on NK cells, stimulating these cells to produce interferon- $\gamma$ (IFN $\gamma)$, that in turn promotes NK-cell cytotoxicity [143]. Resting neutrophils also possess the intermediate-affinity IL-2R, and the IL-2-mediated effects on these cells include resistance to apoptosis [144], enhanced anti-fungal activity [145], and increased protein synthesis and cytokine pro- 
duction [146-148]. Jung et al. [149] reported that CD25 is expressed at the surface of activated $B$ cells and that recombinant IL-2 stimulates their proliferation, thus confirming the existence of a direct effect of IL-2 on B cells, as had been previously proposed by Swain et al. [150] and Parker [151]. Monocytes also constitutively express the intermediate affinity IL-2R [152], and CD25 expression can be induced at the cell surface upon activation with various stimuli, including LPS [153, 154]; moreover, after activation, the supernatants of activated monocytes have high levels of sCD25 [153]. Consistent with these findings are the gene expression profiling results of Martinez et al. [155] regarding monocyte-to-macrophage differentiation and polarization. These results show that classically polarized M1 macrophages, which are induced by IFN $\gamma$ with or without microbial stimuli such as LPS or cytokines such as granulocyte-macrophage colony-stimulating factor, have higher CD25 transcript levels than nonclassically activated M2 macrophages.

The IL-2/IL-2R interaction may also have functions outside of the immune system. IL-2 is able to augment endothelial cell proliferation and hence vascularization [156]. Other studies have shown that IL-2 affects enterocyte ion secretion and proliferation [157], and it has also been demonstrated to be an important neuroregulatory molecule implicated in neurite survival and extension, oligodendrocyte proliferation, hypothalamic-pituitary function and analgesia [158].

\section{Conclusion}

Although the IL-2/IL-2R signaling pathway has been the focus of numerous studies, certain aspects of its molecular regulation are not well characterized, especially in non- $\mathrm{T}$ cells, and a more complete understanding of the pathway is necessary to discern the functional basis of the genetic association between the IL-2-IL-21 and IL-2RA/CD25 gene regions and T1D in humans. Genetic variation in these regions may promote T1D susceptibility by influencing transcription and/or splicing and hence IL-2 and CD25 expression at the protein level in different immune cell subsets; thus, there is a need to establish links between the genetic variation and immune cell phenotypes and functions in humans, which can be further investigated and validated in mouse models. The detection and characterization of genetically determined immunophenotypes should aid in elucidating disease mechanisms, and may enable future monitoring of disease initiation and progression in prediabetic subjects and of responses to therapeutic intervention.
Acknowledgments CAD is supported by a Wellcome Trust 4-Year $\mathrm{Ph} . \mathrm{D}$. Program in Infection and Immunity Studentship. LSW is supported by grants from the Juvenile Diabetes Research Foundation (JDRF) and the Wellcome Trust and LSW is a Juvenile Diabetes Research Foundation/Wellcome Trust Principal Research Fellow. The Cambridge Institute for Medical Research is the recipient of a Wellcome Trust Strategic Award (079895).

Open Access This article is distributed under the terms of the Creative Commons Attribution Noncommercial License which permits any noncommercial use, distribution, and reproduction in any medium, provided the original author(s) and source are credited.

\section{References}

1. Davies JL, Kawaguchi Y, Bennett ST, et al. A genome-wide search for human type-1 diabetes susceptibility genes. Nature. 1994;371:130-6.

2. Field LL. Genetic linkage and association studies of Type I diabetes: challenges and rewards. Diabetologia. 2002;45:21-35.

3. She JX. Susceptibility to type I diabetes: HLA-DQ and DR revisited. Immunol Today 1996;17:323-9.

4. Wicker LS, Todd JA, Peterson LB. Genetic control of autoimmune diabetes in the NOD mouse. Annu Rev Immunol. 1995; 13:179-200.

5. Atkinson MA, Eisenbarth GS. Type 1 diabetes: new perspectives on disease pathogenesis and treatment. Lancet. 2001;358:221-9.

6. Gottlieb PA, Eisenbarth GS. Diagnosis and treatment of preinsulin dependent diabetes. Annu Rev Med. 1998;49:391-405.

7. Burton PR, Clayton DG, Cardon LR, et al. Genome-wide association study of 14,000 cases of seven common diseases and 3,000 shared controls. Nature. 2007;447:661-78.

8. Todd JA, Walker NM, Cooper JD, et al. Robust associations of four new chromosome regions from genome-wide analyses of type 1 diabetes. Nat Genet. 2007;39:857-64.

9. Barratt BJ, Payne F, Lowe CE, et al. Remapping the insulin gene/ IDDM2 locus in type 1 diabetes. Diabetes. 2004;53:1884-9.

10. Ueda H, Howson JMM, Esposito L, et al. Association of the Tcell regulatory gene CTLA4 with susceptibility to autoimmune disease. Nature. 2003;423:506-11.

11. Begovich AB, Carlton VEH, Honigberg LA, et al. A missense single-nucleotide polymorphism in a gene encoding a protein tyrosine phosphatase (PTPN22) is associated with rheumatoid arthritis. Am J Hum Genet. 2004;75:330-7.

12. Bottini N, Musumeci L, Alonso A, et al. A functional variant of lymphoid tyrosine phosphatase is associated with type I diabetes. Nat Genet. 2004;36:337-8.

13. Smyth D, Cooper JD, Collins JE, et al. Replication of an association between the lymphoid tyrosine phosphatase locus ( $L Y P / P T P N 22)$ with type 1 diabetes, and evidence for its role as a general autoimmunity locus. Diabetes. 2004;53:3020-3.

14. Lowe CE, Cooper JD, Brusko T, et al. Large-scale genetic fine mapping and genotype-phenotype associations implicate polymorphism in the IL2RA region in type 1 diabetes. Nat Genet. 2007;39:1074-82.

15. Vella A, Cooper JD, Lowe CE, et al. Localization of a type 1 diabetes locus in the IL2RA/CD25 region by use of tag singlenucleotide polymorphisms. Am J Hum Genet. 2005;76:773-9.

16. Lyons PA, Armitage N, Argentina F, et al. Congenic mapping of the type 1 diabetes locus, $l d d 3$, to a $780-\mathrm{kb}$ region of mouse chromosome 3: Identification of a candidate segment of ancestral DNA by haplotype mapping. Genome Res. 2000;10:446-53. 
17. Podolin PL, Wilusz MB, Cubbon RM, et al. Differential glycosylation of interleukin 2, the molecular basis for the NOD Idd 3 type 1 diabetes gene? Cytokine. 2000;12:477-82.

18. Wicker LS, Clark J, Fraser HI, et al. Type 1 diabetes genes and pathways shared by humans and NOD mice. J Autoimmun. 2005;25:29-33.

19. Yamanouchi J, Rainbow D, Serra P, et al. Interleukin-2 gene variation impairs regulatory $\mathrm{T}$ cell function and causes autoimmunity. Nat Genet. 2007;39:329-37.

20. del Rio R, Noubade R, Subramanian M, et al. SNPs upstream of the minimal promoter control IL-2 expression and are candidates for the autoimmune disease-susceptibility locus Aod2/Idd3/Eae3. Genes and Immunity. 2008;9:115-21.

21. Chapman JM, Cooper JD, Todd JA, et al. Detecting disease associations due to linkage disequilibrium using haplotype tags: A class of tests and the determinants of statistical power. Hum Hered. 2003;56:18-31.

22. Johnson GCL, Esposito L, Barratt BJ, et al. Haplotype tagging for the identification of common disease genes. Nat Genet. 2001;29:233-7.

23. Qu HQ, Montpetit A, Ge B, et al. Toward further mapping of the association between the IL2RA locus and type 1 diabetes. Diabetes. 2007;56:1174-6.

24. Kim HP, Imbert J, Leonard WJ. Both integrated and differential regulation of components of the IL-2/IL-2 receptor system. Cytokine Growth Factor Rev. 2006;7:349-66.

25. Klose RJ, Bird AP. Genomic DNA methylation: the mark and its mediators. Trends Biochem Sci. 2006;31:89-97.

26. Roh TY, Ngau WC, Cui KR, et al. High-resolution genome-wide mapping of histone modifications. Nat Biotechnol. 2004;22: 1013-6.

27. Kramer S, Schimpl A, Hunig T. Immunopathology of interleukin (IL)2-deficient mice - thymus dependence and suppression by thymus-dependent cells with an intact IL-2 gene. J Exp Med. 1995;182:1769-76.

28. Sadlack B, Merz H, Schorle H, et al. Ulcerative colitis-like disease in mice with a disrupted interleukin-2 gene. Cell. 1993;75:253-61.

29. Schorle H, Holtschke T, Hunig T, et al. Development and function of T-cells in mice rendered interleukin- 2 deficient by gene targeting. Nature. 1991;352:621-4.

30. Willerford DM, Chen JZ, Ferry JA, et al. Interleukin-2 receptoralpha chain regulates the size and content of the peripheral lymphoid compartment. Immunity. 1995;3:521-30.

31. Teuscher C, Wardell BB, Lunceford JK, et al. Aod2, the locus controlling development of atrophy in neonatal thymectomyinduced autoimmune ovarian dysgenesis, co-localizes with $\mathrm{Il2}$, Fgfb, and Idd3. J Exp Med. 1996;183:631-7.

32. Encinas JA, Wicker LS, Peterson LB, et al. QTL influencing autoimmune diabetes and encephalomyelitis map to a $0.15-\mathrm{cM}$ region containing Il2. Nat Genet. 1999;21:158-60.

33. Boulard O, Fluteau G, Eloy L, et al. Genetic analysis of autoimmune sialadenitis in nonobese diabetic mice: A major susceptibility region on chromosome 1. J Immunol. 2002;168: 4192-201.

34. Cha S, Nagashima H, Brown VB, et al. Two NOD Iddassociated intervals contribute synergistically to the development of autoimmune exocrinopathy (Sjögren's syndrome) on a healthy murine background. Arthritis Rheum. 2002; 46:1390-8.

35. Pearson T, Weiser P, Markees TG, et al. Islet allograft survival induced by costimulation blockade in NOD mice is controlled by allelic variants of Idd3. Diabetes. 2004;53:1972-8.

36. Gordon EJ, Wicker LS, Peterson LB, et al. Autoimmune diabetes and resistance to xenograft transplantation tolerance in NOD mice. Diabetes. 2005;54:107-15.
37. Martinez X, Kreuwel HTC, Redmond WL, et al. CD8(+) T cell tolerance in nonobese diabetic mice is restored by insulin-dependent diabetes resistance alleles. J Immunol. 2005;175: 1677-85.

38. van Heel DA, Franke L, Hunt KA, et al. A genome-wide association study for celiac disease identifies risk variants in the region harboring IL2 and IL21. Nat Genet. 2007;39:827-9.

39. Zhernakova A, Alizadeh BZ, Bevova M, et al. Novel association in chromosome $4 \mathrm{q} 27$ region with rheumatoid arthritis and confirmation of type 1 diabetes point to a general risk locus for autoimmune diseases. Am J Hum Genet. 2007;81:1284-8.

40. Brand OJ, Lowe CE, Heward JM, et al. Association of the interleukin-2 receptor alpha (IL-2R alpha)/CD25 gene region with Graves' disease using a multilocus test and tag SNPs. Clin Endocrinol (Oxf). 2007;66:508-12.

41. Hafler DA, Compston A, Sawcer S, et al. Risk alleles for multiple sclerosis identified by a genomewide study. N Engl J Med. 2007;357:851-62.

42. Caudy AA, Reddy ST, Chatila T, et al. CD25 deficiency causes an immune dysregulation, polyendocrinopathy, enteropathy, Xlinked-like syndrome, and defective IL-10 expression from CD4 lymphocytes. J Allergy Clin Immunol. 2007;119:482-7.

43. Sharfe N, Dadi HK, Shahar M, et al. Human immune disorder arising from mutation of the alpha chain of the interleukin-2 receptor. Proc Natl Acad Sci USA. 1997;94:3168-71.

44. Kozyrev SV, Abelson AK, Wojcik J, et al. Functional variants in the B-cell gene BANK1 are associated with systemic lupus erythematosus. Nat Genet. 2008;40:211-6.

45. Leonard WJ, Depper JM, Crabtree GR, et al. Molecular cloning and expression of cDNAs for the human interleukin-2 receptor. Nature. 1984;311:626-31.

46. Leonard WJ, Kronke M, Peffer NJ, et al. Interleukin-2 receptor gene expression in normal human T lymphocytes. Proc Natl Acad Sci USA. 1985;82:6281-5.

47. Neeper MP, Kuo LM, Kiefer MC, et al. Structure-function relationships for the IL-2 receptor system. 3. Tac protein missing aminoacids 102 to 173 (exon 4) is unable to bind IL-2 - detection of spliced protein after L-cell transfection. J Immunol 1987;138:3532-8.

48. Horiuchi S, Koyanagi Y, Tanaka Y, et al. Altered interleukin-2 receptor alpha-chain is expressed in human T-cell leukaemia virus type-I-infected T-cell lines and human peripheral blood mononuclear cells of adult T-cell leukaemia patients through an alternative splicing mechanism. Immunology. 1997;91:28-34.

49. Eicher DM, Damjanovich S, Waldmann TA. Oligomerization of IL-2R alpha. Cytokine. 2002;17:82-90.

50. Tsytsikov VN, Yurovsky VV, Atamas SP, et al. Identification and characterization of two alternative splice variants of human interleukin-2. J Biol Chem. 1996;271:23055-60.

51. Minami Y, Kono T, Miyazaki T, et al. The IL-2 receptor complex - its structure, function, and target genes. Annu Rev Immunol. 1993;11:245-68.

52. Nelson BH, Willerford DM. Biology of the interleukin-2 receptor. Advances in Immunology. 1998;70 70:1-81.

53. Rickert M, Wang XQ, Boulanger MJ, et al. The structure of interleukin-2 complexed with its alpha receptor. Science. 2005;308:1477-80.

54. Norman DG, Barlow PN, Baron $\mathrm{M}$, et al. 3-dimensional structure of a complement control protein module in solution. $\mathrm{J}$ Mol Biol. 1991;219:717-25.

55. Shackelford DA, Trowbridge IS. Evidence for 2 extracellular domains in the human interleukin-2 receptor - Localization of IL2 binding. EMBO J. 1986;5:3275-80.

56. Stauber DJ, Debler EW, Horton PA, et al. Crystal structure of the IL-2 signaling complex: Paradigm for a heterotrimeric cytokine receptor. Proc Natl Acad Sci USA. 2006;103:2788-93. 
57. Wang XQ, Rickert M, Garcia KC. Structure of the quaternary complex of interleukin-2 with its alpha, beta, and gamma(c) receptors. Science. 2005;310:1159-63.

58. Lin JX, Mietz J, Modi WS, et al. Cloning of human Stat5B Reconstitution of interleukin-2-induced Stat5A and Stat5B DNA binding activity in COS-7 cells. J Biol Chem. 1996;271:10738-44.

59. Ellery JM, Nicholls PJ. Alternate signalling pathways from the interleukin-2 receptor. Cytokine Growth Factor Rev. 2002;13: $27-40$.

60. Kovanen PE, Young L, Al-Shami A, et al. Global analysis of IL2 target genes: identification of chromosomal clusters of expressed genes. Int Immunol. 2005;17:1009-21.

61. Malek TR. The biology of interleukin-2. Annu Rev Immunol. 2008;26:453-79.

62. Eicher DM, Waldmann TA. IL-2R alpha on one cell can present IL-2 to IL-2R beta/gamma(c) on another cell to augment IL-2 signaling. J Immunol. 1998;161:5430-7.

63. Mier JW, Gallo RC. Purification and some characteristics of human T-cell growth-factor from phytohemagglutinin-stimulated lymphocyte-conditioned media. Proc Natl Acad Sci USA. 1980;77:6134-8.

64. Malek TR, Yu AX, Scibelli P, et al. Broad programming by IL-2 receptor signaling for extended growth to multiple cytokines and functional maturation of antigen-activated $\mathrm{T}$ cells. J Immunol. 2001;166:1675-83.

65. Lin JX, Leonard WJ. Signaling from the IL-2 receptor to the nucleus. Cytokine Growth Factor Rev. 1997;8:313-32.

66. Gong DP, Malek TR. Cytokine-dependent blimp-1 expression in activated $\mathrm{T}$ cells inhibits IL-2 production. J Immunol. 2007;178:242-52.

67. Villarino AV, Tato CM, Stumhofer JS, et al. Helper T cell IL-2 production is limited by negative feedback and STAT-dependent cytokine signals. J Exp Med. 2007;204:65-71.

68. Lenardo MJ. Fas and the art of lymphocyte maintenance. J Exp Med. 1996;183:721-4.

69. Malek TR, Bayer AL. Tolerance, not immunity, crucially depends on IL-2. Nat Rev Immunol. 2004;4:665-74.

70. Dooms H, Wolslegel K, Lin P, et al. Interleukin-2 enhances CD4+ $\mathrm{T}$ cell memory by promoting the generation of IL-7R alphaexpressing cells. J Exp Med. 2007;204:547-57.

71. Leung DT, Morefield S, Willerford DM. Regulation of lymphoid homeostasis by IL-2 receptor signals in vivo. J Immunol. 2000;164:3527-34.

72. Bachmann MF, Wolint P, Walton S, et al. Differential role of IL$2 \mathrm{R}$ signaling for $\mathrm{CD} 8(+) \mathrm{T}$ cell responses in acute and chronic viral infections. Eur J Immunol. 2007;37:1502-12.

73. Williams MA, Tyznik AJ, Bevan MJ. Interleukin-2 signals during priming are required for secondary expansion of CD8 $(+)$ memory T cells. Nature. 2006;441:890-3.

74. Sakaguchi S. Naturally arising $\mathrm{CD} 4(+)$ regulatory $\mathrm{T}$ cells for immunologic self-tolerance and negative control of immune responses. Annu Rev Immunol. 2004;2:531-62.

75. Sakaguchi S, Ono M, Setoguchi R, et al. Foxp3+ CD25+ CD4+ natural regulatory $\mathrm{T}$ cells in dominant self-tolerance and autoimmune disease. Immunol Rev. 2006;212:8-27.

76. Shevach EM. CD4+ CD25+ suppressor T cells: more questions than answers. Nat Rev Immunol. 2002;2:389-400.

77. Toda A, Piccirillo CA. Development and function of naturally occurring CD4+CD25+ regulatory $\mathrm{T}$ cells. J Leukoc Biol. 2006;80:458-70

78. Sakaguchi S, Sakaguchi N, Asano M, et al. Immunological selftolerance maintained by activated T-cells expressing IL-2 receptor alpha-chains (CD25) - Breakdown of a single mechanism of self-tolerance causes various autoimmune diseases. J Immunol. 1995;155:1151-64.
79. Fontenot JD, Gavin MA, Rudensky AY. Foxp3 programs the development and function of $\mathrm{CD} 4+\mathrm{CD} 25+$ regulatory $\mathrm{T}$ cells. Nat Immunol. 2003;4:330-6.

80. Hori S, Nomura T, Sakaguchi S. Control of regulatory T cell development by the transcription factor Foxp3. Science. 2003;299:1057-61

81. Khattri R, Cox T, Yasayko SA, et al. An essential role for Scurfin in $\mathrm{CD} 4(+) \mathrm{CD} 25(+) \mathrm{T}$ regulatory cells. Nat Immunol. 2003;4: 337-42.

82. Bennett CL, Christie J, Ramsdell F, et al. The immune dysregulation, polyendocrinopathy, enteropathy, X-linked syndrome (IPEX) is caused by mutations of FOXP3. Nat Genet. 2001;27:20-1.

83. Gambineri E, Torgerson TR, Ochs HD. Immune dysregulation, polyendocrinopathy, enteropathy, and X-linked inheritance (IPEX), a syndrome of systemic autoimmunity caused by mutations of FOXP3, a critical regulator of T-cell homeostasis. Curr Opin Rheumatol. 2003;15:430-5.

84. Wildin RS, Ramsdell F, Peake J, et al. X-linked neonatal diabetes mellitus, enteropathy and endocrinopathy syndrome is the human equivalent of mouse scurfy. Nat Genet. 2001;27:18-20.

85. Chatila TA, Blaeser F, Ho N, et al. JM2, encoding a fork headrelated protein, is mutated in X-linked autoimmunity-allergic disregulation syndrome. J Clin Invest. 2000;106:R75-81.

86. Su L, Creusot RJ, Gallo EM, et al. Murine CD4(+) CD25(+) regulatory $\mathrm{T}$ cells fail to undergo chromatin remodeling across the proximal promoter region of the IL-2 gene. J Immunol. 2004;173:4994-5001.

87. Ono M, Yaguchi H, Ohkura N, et al. Foxp3 controls regulatory T-cell function by interacting with AML1/Runx1. Nature. 2007;446:685-9.

88. Wu YQ, Borde M, Heissmeyer V, et al. FOXP3 controls regulatory $\mathrm{T}$ cell function through cooperation with NFAT. Cell. 2006; $126: 375-87$.

89. Salomon B, Lenschow DJ, Rhee L, et al. B7/CD28 costimulation is essential for the homeostasis of the CD4(+)CD25(+) immunoregulatory $\mathrm{T}$ cells that control autoimmune diabetes. Immunity. 2000;12:431-40.

90. Tang QZ, Henriksen KJ, Boden EK, et al. Cutting edge: CD28 controls peripheral homeostasis of CD4(+)CD25(+). J Immunol. 2003; 171:3348-52.

91. Tai XG, Cowan M, Feigenbaum L, et al. CD28 costimulation of developing thymocytes induces Foxp3 expression and regulatory $\mathrm{T}$ cell differentiation independently of interleukin 2 . Nat Immunol. 2005;6:152-62.

92. Bayer AL, Yu AX, Malek TR. Function of the IL-2R for thymic and peripheral CD4(+)CD25(+) Foxp3(+) T regulatory cells. J Immunol. 2007;178:4062-71.

93. Liston A, Siggs OM, Goodnow CC. Tracing the action of IL-2 in tolerance to islet-specific antigen. Immunol Cell Biol. 2007;85: $338-42$.

94. Jaeckel E, Kretschmer K, Apostolou I, et al. Instruction of Treg commitment in peripheral $\mathrm{T}$ cells is suited to reverse autoimmunity. Semin Immunol. 2006;18:89-92.

95. Fontenot JD, Rasmussen JP, Gavin MA, et al. A function for interleukin 2 in Foxp3-expressing regulatory $\mathrm{T}$ cells. Nat Immunol. 2005;6:1142-51.

96. Setoguchi R, Hori S, Takahashi T, et al. Homeostatic maintenance of natural Foxp3(+) $\mathrm{CD} 25(+) \mathrm{CD} 4(+)$ regulatory $\mathrm{T}$ cells by interleukin (IL)-2 and induction of autoimmune disease by IL-2 neutralization. J Exp Med. 2005;201:723-35.

97. Green EA, Gorelik L, McGregor CM, et al. CD4(+)CD25(+) T regulatory cells control anti-islet $\mathrm{CD} 8(+) \mathrm{T}$ cells through TGFbeta-TGF-beta receptor interactions in type 1 diabetes. Proc Natl Acad Sci USA. 2003;100:10878-83. 
98. Herman AE, Freeman GJ, Mathis D, et al. CD4(+)CD25(+) T regulatory cells dependent on ICOS promote regulation of effector cells in the prediabetic lesion. J Exp Med. 2004;199:1479-89.

99. Chen ZB, Herman AE, Matos M, et al. Where CD4(+) CD25(+) $\mathrm{T}$ reg cells impinge on autoimmune diabetes. J Exp Med. 2005;202:1387-97.

100. Tritt M, Sgouroudis E, d'Hennezel E, et al. Functional waning of naturally occurring $\mathrm{CD} 4(+)$ regulatory T-Cells contributes to the onset of autoimmune diabetes. Diabetes. 2008;57:113-23.

101. Tang Q, Adams JY, Penaranda C, et al. Central role of defective interleukin-2 production in the triggering of islet autoimmune destruction. Immunity. 2008;28:687-97.

102. Shi FD, Flodstrom M, Balasa B, et al. Germ line deletion of the CD1 locus exacerbates diabetes in the NOD mouse. Proc Natl Acad Sci USA. 2001;98:6777-82.

103. Kukreja A, Cost G, Marker J, et al. Multiple immuno-regulatory defects in type-1 diabetes. J Clin Invest. 2002;109:131-40.

104. Brusko TM, Wasserfall CH, Clare-Salzler MJ, et al. Functional defects and the influence of age on the frequency of CD4(+) CD25(+) T-Cells in type 1 diabetes. Diabetes. 2005;54:1407-14.

105. Lindley S, Dayan CM, Bishop A, et al. Defective suppressor function in $\mathrm{CD} 4(+) \mathrm{CD} 25(+)$ T-cells from patients with type 1 diabetes. Diabetes. 2005;54:92-9.

106. Putnam AL, Vendrame F, Dotta F, et al. CD4+CD25(high) regulatory $\mathrm{T}$ cells in human autoimmune diabetes. J Autoimmun. 2005;24:55-62.

107. Tree TIM, Roep BO, Peakman M. A mini meta-analysis of studies on CD4(+)CD25(+) T cells in human type 1 diabetesReport of the Immunology of Diabetes Society T Cell Workshop. Immunology of Diabetes IV: Progress in Our Understanding. 2006;1079:9-18.

108. Brusko T, Wasserfall C, McGrail K, et al. No alterations in the frequency of FOXP3(+) regulatory T-cells in type 1 diabetes. Diabetes. 2007;56:604-12.

109. Vukmanovic-Stejic M, Zhang Y, Cook JE, et al. Human CD4(+) $\mathrm{CD} 25(\mathrm{hi}) \mathrm{Foxp} 3(+)$ regulatory $\mathrm{T}$ cells are derived by rapid turnover of memory populations in vivo. J Clin Invest. 2006;116:2423-33.

110. Roncador G, Brown PJ, Maestre L, et al. Analysis of FOXP3 protein expression in human $\mathrm{CD} 4(+) \mathrm{CD} 25(+)$ regulatory $\mathrm{T}$ cells at the single-cell level. Eur J Immunol. 2005;35:1681-91.

111. Baecher-Allan C, Brown JA, Freeman GJ, et al. CD4+CD25 (high) regulatory cells in human peripheral blood. J Immunol. 2001;167:1245-53.

112. Baecher-Allan C, Viglietta V, Hafler DA. Inhibition of human $\mathrm{CD} 4(+) \mathrm{CD} 25(+$ high) regulatory $\mathrm{T}$ cell function. J Immunol. 2002;169:6210-7.

113. Gregori S, Giarratana N, Smiroldo S, et al. Dynamics of pathogenic and suppressor $\mathrm{T}$ cells in autoimmune diabetes development. J Immunol. 2003;171:4040-7.

114. Pop SM, Wong CP, Culton DA, et al. Single cell analysis shows decreasing FoxP3 and TGF beta 1 coexpressing CD4(+)CD25(+) regulatory $\mathrm{T}$ cells during autoimmune diabetes. J Exp Med. 2005;201:1333-46.

115. You S, Belghith M, Cobbold S, et al. Autoimmune diabetes onset results from qualitative rather than quantitative age-dependent changes in pathogenic T-cells. Diabetes. 2005;54:1415-22.

116. Waithman J, Gebhardt T, Davey GM, et al. Cutting edge: Enhanced IL-2 signaling can convert self-specific $\mathrm{T}$ cell response from tolerance to autoimmunity. J Immunol. 2008; 180:5789-93.

117. Rubin LA, Nelson DL. The soluble interleukin-2 receptor: biology, function, and clinical application. Ann Intern Med. 1990;113:619-27.
118. Rubin LA, Kurman CC, Fritz ME, et al. Soluble interleukin-2 receptors are released from activated human lymphoid cells in vitro. J Immunol. 1985;135:3172-7.

119. Junghans RP, Stone AL, Lewis MS. Biophysical characterization of a recombinant soluble interleukin 2 receptor (Tac) - Evidence for a monomeric structure. J Biol Chem. 1996;271:10453-60.

120. Jacques Y, Lemauff B, Godard A, et al. Biochemical study of a recombinant soluble interleukin-2 receptor - Evidence for a homodimeric structure. J Biol Chem. 1990;265:20252-8.

121. Fisson S, Darrasse-Jeze G, Litvinova E, et al. Continuous activation of autoreactive CD4+ CD25+ regulatory $\mathrm{T}$ cells in the steady state. J Exp Med. 2003;198:737-46.

122. Klein L, Khazaie K, von Boehmer H. In vivo dynamics of antigen-specific regulatory $\mathrm{T}$ cells not predicted from behavior in vitro. Proc Natl Acad Sci USA. 2003;100:8886-91.

123. Walker LS, Chodos A, Eggena M, et al. Antigen-dependent proliferation of CD4+ CD25+ regulatory T cells in vivo. J Exp Med. 2003;198:249-58.

124. Robb RJ, Kutny RM. Structure-function relationships for the IL2 -receptor system 4 . Analysis of the sequence and ligand-binding properties of soluble Tac protein. J Immunol. 1987;139:855-62.

125. Kobayashi H, Tagaya Y, Han ES, et al. Use of an antibody against the soluble interleukin 2 receptor alpha subunit can modulate the stability and biodistribution of interleukin 2 . Cytokine. 1999;11:1065-75.

126. Kondo N, Kondo S, Shimizu A, et al. A soluble anchorminus interleukin-2 receptor suppresses in vitro interleukin-2-mediated immune responses. Immunol Lett. 1988;19:299-308.

127. Rubinstein MP, Kovar M, Purton JF, et al. Converting IL-15 to a superagonist by binding to soluble IL-15R alpha. Proc Natl Acad Sci USA. 2006;103:9166-71.

128. Treiger BF, Leonard WJ, Svetlik P, et al. A secreted form of the human interleukin-2 receptor encoded by an anchorminus cDNA. J Immunol. 1986;136:4099-105.

129. Nervi S, Atlan-Gepner C, Fossat C, et al. Constitutive impaired TCR/CD3-mediated activation of T cells in IDDM patients coexist with normal co-stimulation pathways. J Autoimmun. 1999;13:247-55.

130. Lang J, Bellgrau D. A T-cell functional phenotype common among autoimmune-prone rodent strains. Scand J Immunol. 2002;55:546-59.

131. Granucci F, Vizzardelli C, Pavelka N, et al. Inducible IL-2 production by dendritic cells revealed by global gene expression analysis. Nat Immunol. 2001;2:882-8.

132. Jiang SP, Game DS, Davies D, et al. Activated CD1d-restricted natural killer T cells secrete IL-2: innate help for CD4(+)CD25(+) regulatory T cells? Eur J Immunol. 2005;35:1193-200.

133. Yui MA, Sharp LL, Havran WL, et al. Preferential activation of an IL-2 regulatory sequence transgene in TCR gamma delta and NKT cells: Subset-specific differences in IL-2 regulation. J Immunol. 2004;172:4691-9.

134. Feau S, Facchinetti V, Granucci F, et al. Dendritic cell-derived IL-2 production is regulated by IL-15 in humans and in mice. Blood. 2005;105:697-702.

135. Freudenthal PS, Steinman RM. The distinct surface of human blood dendritic cells, as observed after an improved isolation method. Proc Natl Acad Sci USA. 1990;87:7698-702.

136. Pollard AM, Lipscomb MF. Characterization of murine lung dendritic cells - Similarities to langerhans cells and thymic dendritic cells. J Exp Med. 1990;172:159-67.

137. Naranjo-Gomez M, Oliva H, Climent N, et al. Expression and function of the IL-2 receptor in activated human plasmacytoid dendritic cells. Eur J Immunol. 2007;37:1764-72.

138. Mnasria K, Lagaraine C, Velge-Roussel F et al. Anti-CD25 antibodies affect cytokine synthesis pattern of human dendritic 
cells and decrease their ability to prime allogeneic CD4+ T cells. J Leukoc Biol. 2008

139. Matsuda JL, Zhang QJ, Ndonye R, et al. T-bet concomitantly controls migration, survival, and effector functions during the development of $\mathrm{V}$ alpha 14i NKT cells. Blood. 2006;107: 2797-805.

140. Henney CS, Kuribayashi K, Kern DE, et al. Interleukin-2 augments natural-killer cell activity. Nature. 1981;291:335-8.

141. London L, Perussia B, Trinchieri G. Induction of proliferation in vitro of resting human natural-killer cells-IL-2 induces into cell-cycle most peripheral-blood NK cells, but only a minor subset of low-density T cells. J Immunol. 1986;137:3845-54.

142. Ortaldo JR, Mason AT, Gerard JP, et al. Effects of natural and recombinant IL-2 on regulation of IFN-gamma production and natural-killer activity - Lack of involvement of the Tac antigen for these immunoregulatory effects. J Immunol. 1984;133:779-83.

143. Granucci F, Zanoni I, Pavelka N, et al. A contribution of mouse dendritic cell-derived IL-2 for NK cell activation. J Exp Med. 2004;200:287-95.

144. Pericle F, Liu JH, Diaz JI, et al. Interleukin-2 prevention of apoptosis in human neutrophils. Eur J Immunol. 1994;24:440-4.

145. Djeu JY, Liu JH, Wei S, et al. Function associated with IL-2 receptor-beta on human neutrophils - mechanism of activation of antifungal activity against Candida albicans by IL-2. J Immunol. 1993;150:960-70

146. Girard D, Gosselin J, Heitz D, et al. Effects of interleukin-2 on gene expression in human neutrophils. Blood. 1995;86:1170-6.

147. Wei S, Blanchard DK, Liu JH, et al. Activation of tumornecrosis-factor-alpha production from human neutrophils by IL-2 via IL-2R-beta. J Immunol. 1993;150:1979-87.

148. Wei S, Liu JH, Blanchard DK, et al. Induction of IL-8 gene expression in human polymorphonuclear neutrophils by recombinant IL-2. J Immunol. 1994;152:3630-6.
149. Jung LKL, Hara T, Fu SM. Detection and functional studies of p60-65 (Tac antigen) on activated human B cells. J Exp Med. 1984;160:1597-602.

150. Swain SL, Dennert G, Warner JF, et al. Culture supernatants of a stimulated T-cell line have helper activity that acts synergistically with interleukin-2 in the response of B-cells to antigen. Proc Natl Acad Sci USA. 1981;78:2517-21.

151. Parker DC. Separable helper factors support B-cell proliferation and maturation to Ig secretion. J Immunol. 1982;129: 469-74.

152. Espinoza-Delgado I, Ortaldo JR, Winklerpickett R, et al. Expression and role of $\mathrm{p} 75$ interleukin-2 receptor on human monocytes. J Exp Med. 1990;171:1821-6.

153. Kniep EM, Strelow I, Lohmannmatthes ML. The monocyte interleukin-2 receptor light chain - production of cell-associated and soluble interleukin-2 receptor by monocytes. Immunology. 1992;75:299-304.

154. Valitutti S, Carbone A, Castellino F, et al. The expression of functional IL-2 receptor on activated macrophages depends on the stimulus applied. Immunology. 1989;67:44-50.

155. Martinez FO, Gordon S, Locati M, et al. Transcriptional profiling of the human monocyte-to-macrophage differentiation and polarization: New molecules and patterns of gene expression. $\mathrm{J}$ Immunol. 2006;177:7303-11.

156. Cozzolino F, Torcia M, Lucibello M, et al. Interferon-alpha and interleukin-2 synergistically enhance basic fibroblast growthfactor synthesis and induce release, promoting endothelial-cell growth. J Clin Invest. 1993;91:2504-12.

157. O'Loughlin EV, Pang GP, Noltorp R, et al. Interleukin 2 modulates ion secretion and cell proliferation in cultured human small intestinal enterocytes. Gut. 2001;49:636-43.

158. Jiang CL, Lu CL. Interleukin-2 and its effects in the central nervous system. Biol Signals Recept. 1998;7:148-56. 